\title{
Artificial Neural Networks for Internal Combustion Engine Performance and Emission Analysis
}

\author{
Anant Bhaskar Garg \\ Centre for Information Technology \\ University of Petroleum \& \\ Energy Studies, Dehradun
}

\author{
Parag Diwan \\ Vice Chancellor \\ University of Petroleum \& \\ Energy Studies, Dehradun
}

\author{
Mukesh Saxena \\ Head, Dept. of Mechanical \\ University of Petroleum \& \\ Energy Studies, Dehradun
}

\begin{abstract}
This paper presents an analytical work for better design system that contributes to the reduction of fuel consumption and emission for vehicle performance. The main technological issue on engines today is to comply with emission standards with cost-effective measures in order to keep the engine price still attractive to customer. The experimental research of engine performance are time consuming and quite expensive. The purpose of this work is to optimize engine performance using artificial neural networks (ANN). Back propagation neural network was used to optimize prediction model performance. The paper analyzed data from various experimental tests in which different engine operating parameters are measured. The paper highlights the framework and suitable model of ANN to optimize several operating parameters of the engine. The optimization includes a range of standards engine-operating conditions, with specified limits in emissions.
\end{abstract}

\section{General Terms}

Artificial Neural Networks, Engine Operation, ANN approaches to management of Engine operations, ANN algorithms, architecture

\section{Keywords}

Artificial Neural Networks, Engine Operation, ANN algorithms, architecture

\section{INTRODUCTION}

The liquid petroleum fuels are a limited and the demand is enormously increasing. The cost of fuel is ever increasing. In order to comply with increasingly stringent emissions standards and meet drivability requirements, modern automobile engines are equipped with an increasing number of subsystems and controlling elements. The result has been increase in the calibration effort required to find the parameter settings that offer the best global competitiveness. Reducing pollutant emissions is a vital and a continuous challenge for the automotive industry. New technologies are being investigated, often with the aim of simultaneously improving performance, fuel economy, and emission characteristics. Thus for obtaining engine fuel consumption and emission in terms of calibration parameters, an engine model is required. Because of highly complex and nonlinear nature of internal combustion engines models used to study are in the form of black-box models [1], [2]. [3], [4], and [5].

A very powerful method among black-box modeling techniques is the artificial neural network modeling which has been widely used in various branches of engineering in recent years [5]. This technique aims to significantly decrease dynamometer test requirements by generating mathematical models of the engine outputs using a smaller subset of dynamometer tests. Once the mathematical models have been developed, the calibration maps can be optimized using techniques such as gradient procedures [2]. Various approaches have been proposed for using ANN to promote modelling and calibration of engines [4]. The ability of Artificial Neural Network as a system identification tool is used to model non-linear behavior of engine operations. Many researchers used ANN for predicting torque, power, specific fuel consumption, and soot formation with speed and injection pressure [6], [7], [8], [9], [10], and [5] found the ANN provides accuracy and simplicity in the analysis of the engine performance. $\mathrm{Wu}$ and Gisca described ANN to model for determining the functioning parameters of the internal combustion engine, such as pressure in cylinders or the airfuel ratio [11], [12].

But in neural network design selection of network topology, the trigger function, learning rule and the criteria or permissible error for stopping the training phase is crucial and done by the designer/engineer. So, it is difficult to predefine the size of the network as there is no fixed method to do it. Despite this issue, neural networks based solution is very efficient in terms of development, time and resources. By experience and working on different architecture, size, and models we can provide real solutions. Thus, we conducted detailed study using different algorithms and chose the one that provides the best results for given set of data of engine parameters. ANN modeling explores the performance and emission of vehicle engine. Based on collected experimental data, ANN correlates engine-operating parameters with the performance parameters and emission characteristics.

Garg discussed extensive literature Review and various applications of ANN [13]. Thus, real-time operation and mapping of complex, non-linear and dynamic patterns in engine operations are challenges to be met in today's engine development. Neural networks architectures, combinations of networks, and different algorithms play an important role on the performance. There is a need to use ANN as a performance critical tool that saves cost and time in developing new models and methodologies for overall engine management. Further it will help in accessing which algorithm is best suitable for a particular situation.

\section{RESEARCH METHODOLOGY}

The ability of ANN to understand and properly classify a problem of highly non-linear relationship has been established and the significant consideration is that once trained effectively ANN can classify new data much faster than it would be possible with analytical model. A neural network is 
a massively parallel-distributed processor that has a natural propensity for storing experimental knowledge and making it available for use. It resembles the brain in two respects [14]: 1. Knowledge is acquired by the network through a learning process. 2. Inter-neuron connection strengths known as synaptic weights are used to store the knowledge. Our inputs parameters are Fuel Injection Angle (degree BTDC), Fuel Injection Pressure $(\mathrm{kgf} / \mathrm{cm} 2)$, Load $(\mathrm{kW}), \mathrm{T}_{\mathrm{FUEL}}(\mathrm{Sec})$ (For 50 CC), Speed (RPM) and outputs are various emissions parameters $\mathrm{CO}(\% \mathrm{Vol}), \mathrm{CO}_{2}(\% \mathrm{Vol}), \mathrm{NO}_{\mathrm{X}}(\mathrm{ppm}), \mathrm{HC}$, SMOKE (\%opacity), and efficiency parameters BTE (\%), BSFC $(\mathrm{kg} / \mathrm{kWh})$.

Experimental data collected to analyze the performance of engine, and ANN architecture are set of above data for training and testing purposes. We performed design and development of alternative neural network architecture, algorithms, and other approaches for the above data and thus finding efficient pattern for engine optimization. More detailed description on ANN can be found in [15] and related to engine in [13]. There are numerous algorithms available for training neural network models and most of them can be viewed as a straightforward application of optimization theory and statistical estimation. These algorithms generally use gradient descent form. This is done by simply taking the derivative of the cost function with respect to the network parameters and then changing those parameters in a gradientrelated direction. Some of the algorithms are Gradient Descent Algorithm, and Levenberg-Marquardt Algorithm. Some types of networks architecture are feed-forward network, Radial Basis Function network that are dealt in this present study.

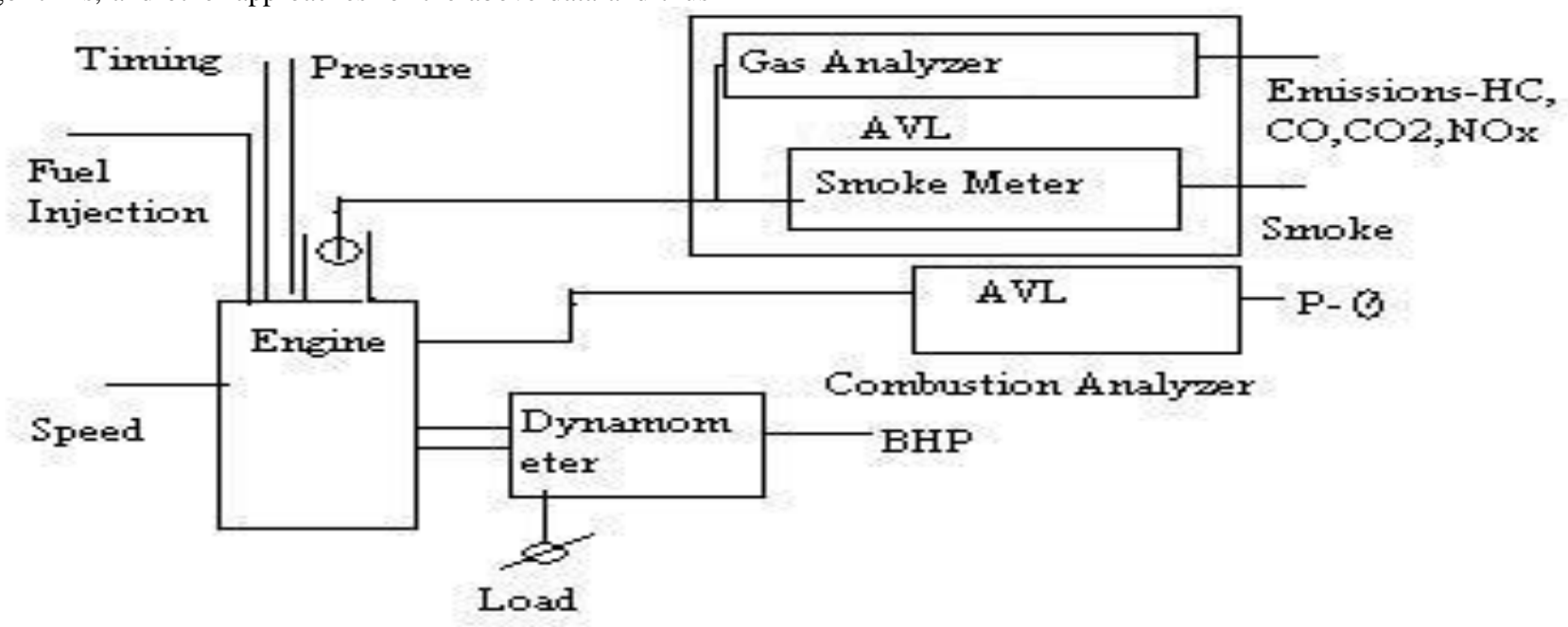

Figure1. Experimental Setup of Engine

\section{EXPERIMENTAL SETUP}

The engine selected for this research is Field Marshal IDI Diesel Engine. This is a single cylinder, water cooled, vertical engine having forced lubrication system. The engine designed for compression ratio $17: 1$, it is $1580 \mathrm{cc}$ engine with bore $\mathrm{x}$ stroke $120 \mathrm{~mm} \times 139.7 \mathrm{~mm}$. The engine is self-governed and designed to operate at $1000 \mathrm{rpm}$. The advance angle of fuel injection for diesel fuel is $20^{\circ}$ and the fuel injection pressure is $175 \mathrm{kgF} / \mathrm{cm}^{2}$. The engine is coupled with single phase AC alternator having rated capacity $7.5 \mathrm{kw}$ at $1500 \mathrm{rpm}$. The efficiency of the alternator as quoted by the manufacturer is $80 \%$. The alternator was coupled with engine with v-belt power transmission system. The main components of experimental set up are alternator, hydraulic loading unit, fuel consumption measuring unit, voltmeter, ammeter, temperature measuring thermocouples, AVL- 437 smoke meters and AVL gas analyzer used for emission measurement as shown in figure 1 . The engine rpm was mounted on vibration isolators to minimize the vibrations. Training and test sample are required for building an ANN prediction models. The training sample is used for ANN model development and the test sample adopted for evaluating the prediction ability of the model. In this study three separate neural networks were developed for each performance, as ANN1, ANN2, and ANN3.

\section{RESULTS AND DISCUSSION}

Diesel engine emissions $\mathrm{CO}, \mathrm{CO} 2, \mathrm{NOx}, \mathrm{HC}$, smoke opacity, and brake specific fuel efficiency, BTE were evaluated using predicted models and compared with experimental results. The graphs below show that the predicted values are close to experimental results which demonstrate applicability of artificial neural network in predicting diesel engine performance from figure 2 to figure 8 .

As shown in graphs except $\mathrm{CO}$ all values for experimental and predicted values matches and in $\mathrm{CO}$ reason is that values are within matching criteria but range is very small -.20 to .60 (\%vol). Modeling techniques such as artificial neural networks and taking their different architecture, activation functions, combination of these can affect the models of ANN. In this paper, ANN are used to create model with backpropagation methods for feed forward architecture based on different learning algorithm. The main objective of learning algorithm is to provide a methodology to teach the network for a given task and predict the output. Performance of the network is judged by calculating the mean squared error for training and test data. Besides this, calculation of coefficient of determination $\mathrm{R}^{2}$ that is absolute fraction of variation found for our model value equal to 0.81 which is more close to 1 . 


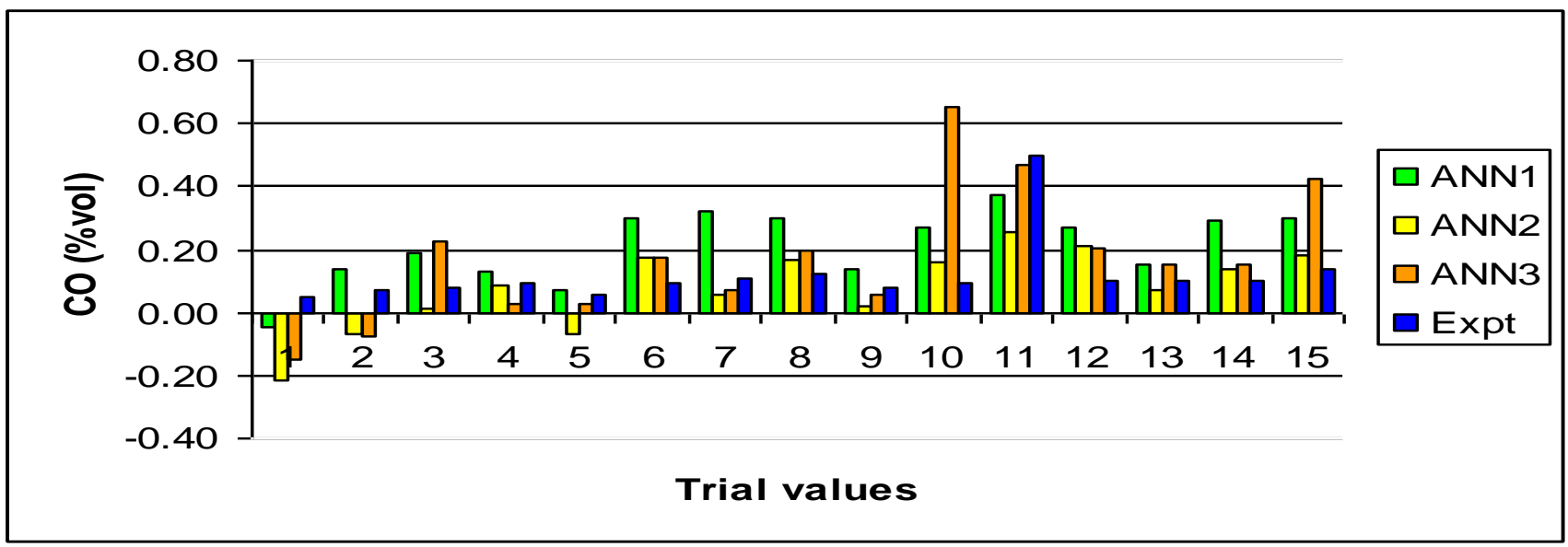

Figure2. Comparisons of ANN1, ANN2, ANN3 predicted results and experimental results for engine CO

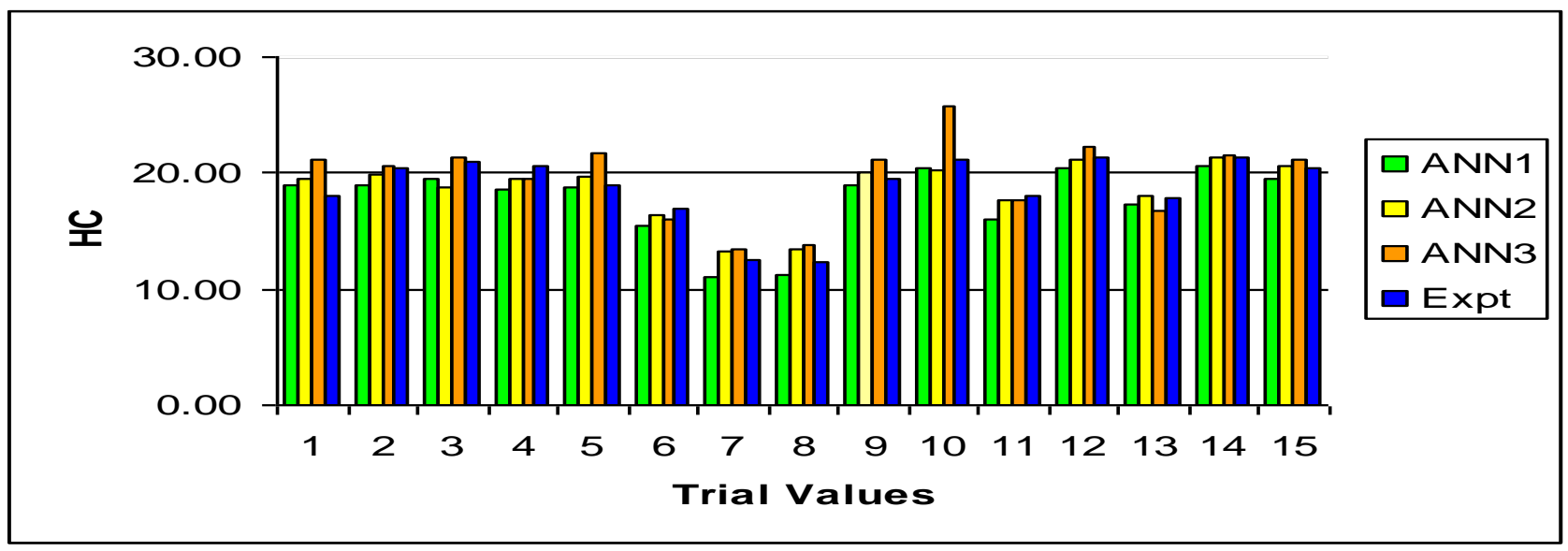

Figure3. Comparisons of ANN1, ANN2, ANN3 predicted results and experimental results for engine HC

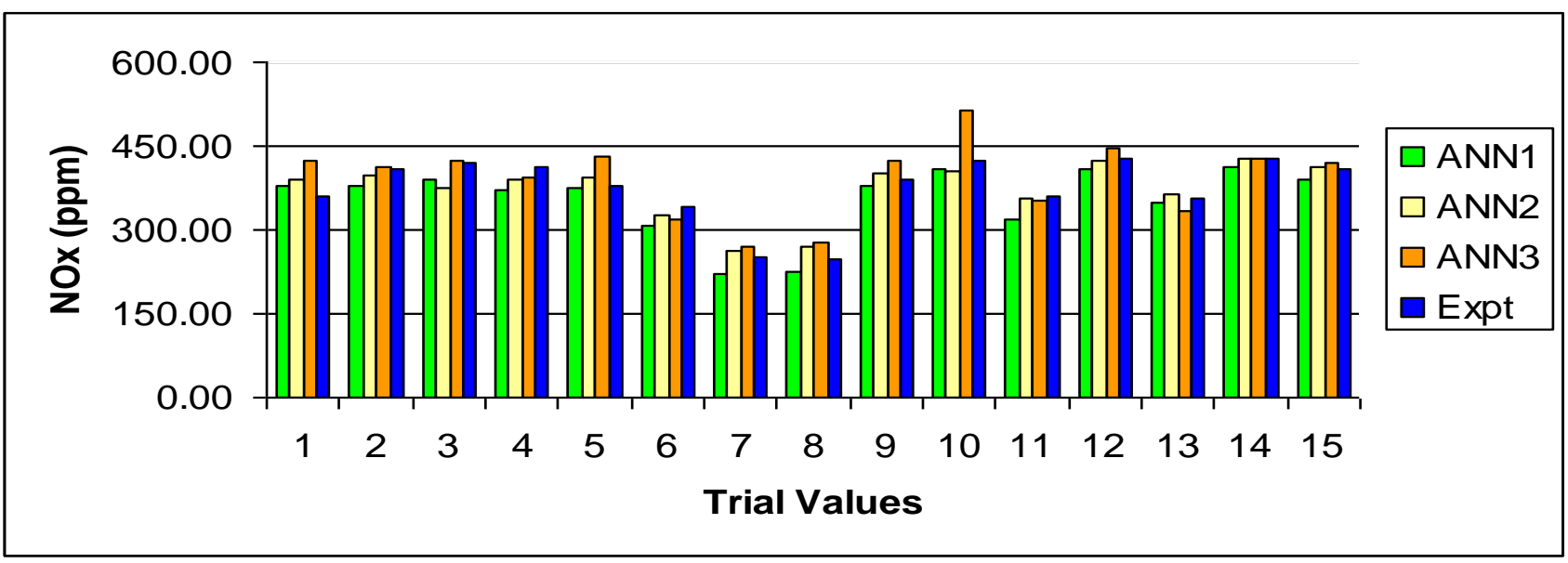

Figure4. Comparisons of ANN1, ANN2, ANN3 predicted results and experimental results for engine NOx 


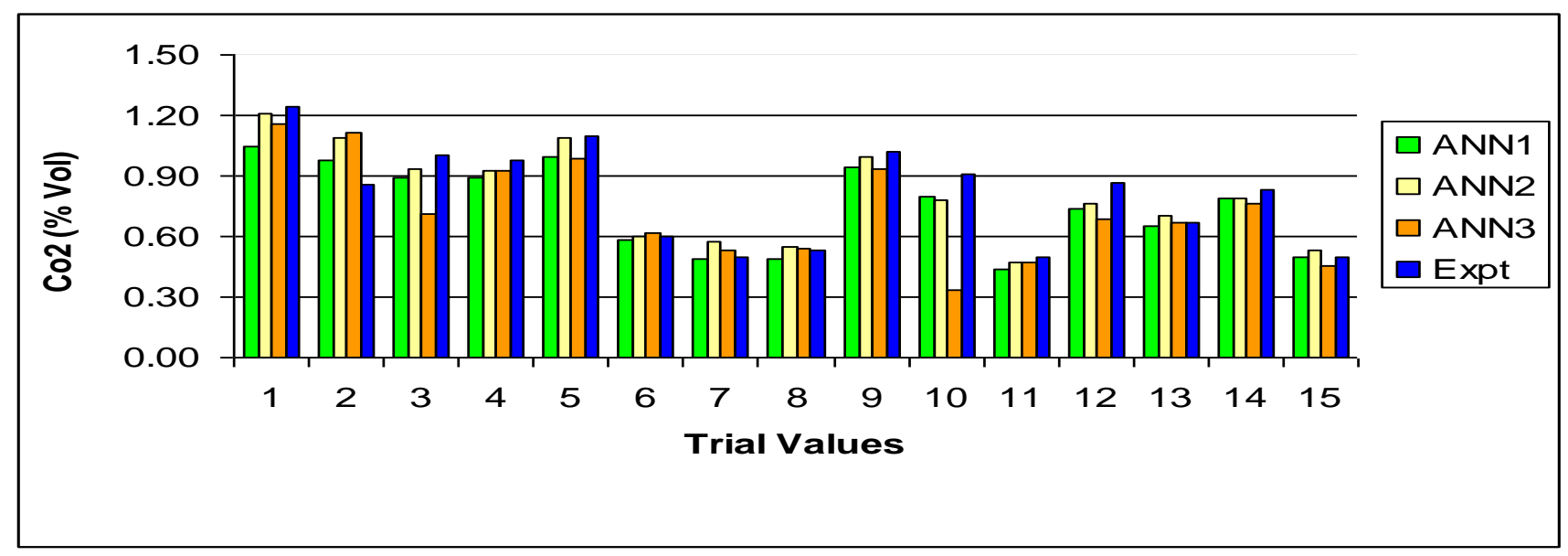

Figure5. Comparisons of ANN1, ANN2, ANN3 predicted results and experimental results for engine $\mathrm{CO}_{2}$

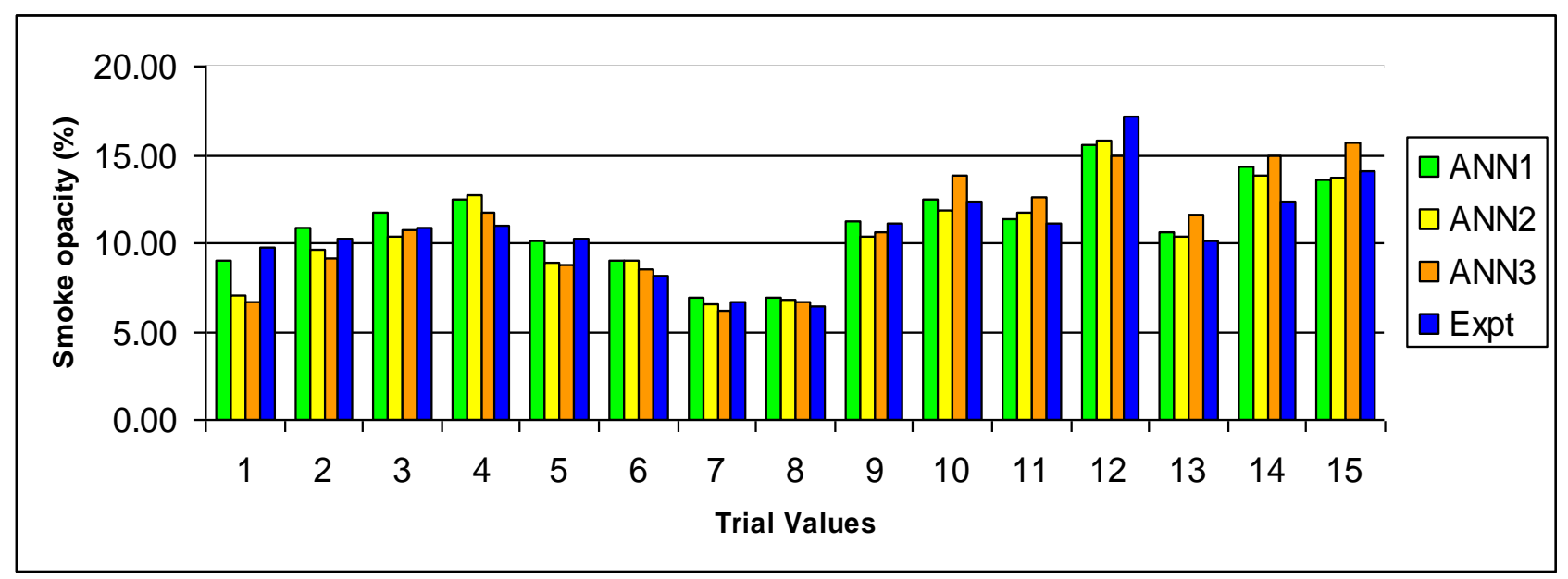

Figure6. Comparisons of ANN1, ANN2, ANN3 predicted results and experimental results for engine Smoke opacity

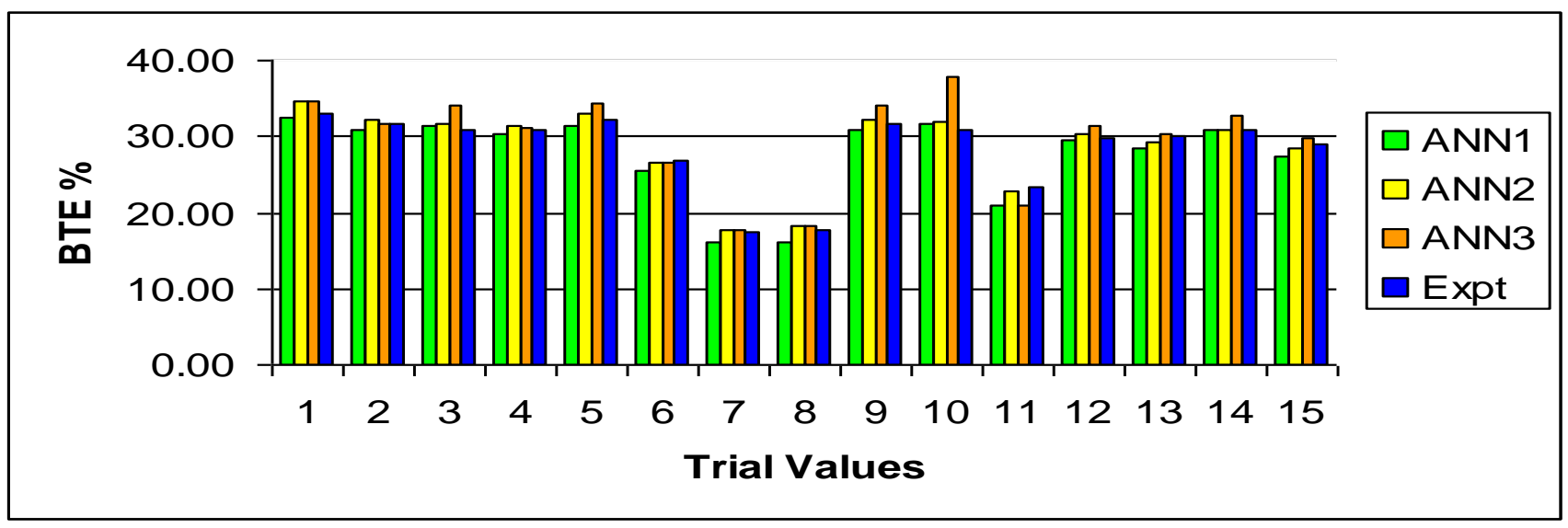

Figure7. Comparisons of ANN1, ANN2, ANN3 predicted results and experimental results for engine BTE 


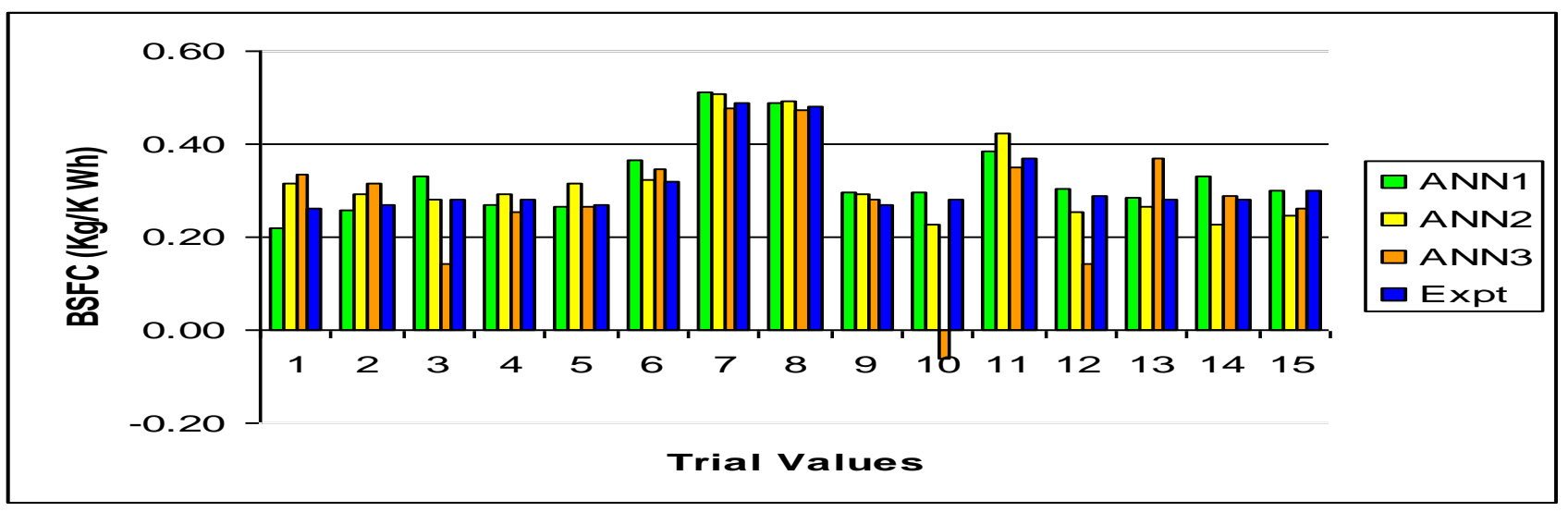

Figure8. Comparisons of ANN1, ANN2, ANN3 predicted results and experimental results for engine BSFC

\section{CONCLUSION}

The paper suggest that there is a need to use ANN as a performance critical tool that saves cost and time in developing new models and methodologies for overall engine management. Prediction models of diesel engine performance parameters have been developed using Artificial Neural Networks. Three sets of prediction model for each performance parameters have been developed by using neural networks. Further it will help in accessing which algorithm is best suitable for a particular situation and in decreasing dynamometer test requirements by generating models of the engine outputs using a smaller subset of dynamometer tests.

\section{ACKNOWLEDGMENTS}

Our thanks to colleagues in the mechanical dept. who have given us experimental data especially Narayan, Ranjit, R.K. Tripathi and P.K. Sahoo. We are thankful to Dr. S. J. Chopra, UPES Chancellor for providing research facility. Part of the work is presented in the national seminar.

\section{REFRENCES}

[1] Rask, E. and Sellnau, M. (2004), Simulation-Based Engine Calibration: Tools, Techniques and Applications, SAE Technical Paper No. 2004-01-1264. Calibration of Aging Diesel Engine with Artificial Neural Networks 531.

[2] Vossoughi, G. R. and Rezazdeh, S. (2005), Opimization of the Calibration for an Internal Combustion Engine Management System using Multi-Objective Genetic Alogrithms, International Journal of Computational Intelligence, Vol.2,No.5, pp.151-161

[3] Alonso, J. M., Alvarruiz, F., Desantes, J. M., Hernández, L., Hernández, V. and Moltó, G. (2007), Combining Neural Networks and Genetic Algorithms to Predict and Reduce Diesel Engine Emissions, IEEE Transactions on Evolutionary Computation, Vol.11, No. 1, pp.46-55.

[4] Desantes, J. M.; Lopez, J. J.; Garcia, J. M. and Hernandez, L. (2002), Application of Neural Networks for Prediction and Optimization of Exhaust Emissions in a H.D. Diesel Engine, SAE Technical Paper No. 01-1144.

[5] Zweiri, Y. H. (2006), Diesel Engine Indicated Torque Estimation Based on Artificial Neural Networks, International Journal of Intelligent Technology, Vol. 2. No. 2, pp. 233-239.

[6] Akcayoli M.A., Can C.R., H. Bulbul, A. Kilicarsalan (2004), Artificial Neural Network Based Modeling of Injection Pressure in Diesel Engines, www.wseas.us/elibrary/conferences/miami2004/papers/4 84-222.pdf

[7] Sekmen Y., Gölcü M. , Erduranlı P., Pancar Y. (2006), Prediction of Performance and Smoke Emission using Artificial Neural Network in a Diesel Engine , Mathematical and computational application, Association for scientific research, Vol.11,3; 205-214

[8] Gholamhassan N., Barat G., Talal Y., Hadi R.(2007), Combustion Analysis of a CI Engine Performance using Waste Cooking Biodiesel Fuel with an Artificial Neural Network Aid, American Journal of Applied Sciences 4 (10): 756-764.

[9] Ghobadian B., Rahimi H., Nikbakht A.M., Najafi G. and Yusaf T.F. (2009), Diesel Engine Performance and Exhaust Emission Analysis using Waste Cooking Biodiesel Fuel with an Artificial Neural Network, Renewable Energy, 34 (4). Pp.976-982.

[10]Tutuncu K. and Allahverdi N. (2009), Modeling the Performance and Emission Characteristics of Diesel Engine and Petrol- Driven Engine by ANN. International Conference on Computer Systems and Technologies, CompSysTech'09.

[11] Wu B., Zoran F., Denise M. K, Gregory L. Ohl, Michael J. Prucka and Eugene DiValentin (2004) Using Artificial Neural Networks for Representingthe Air Flow Rate through a 2.4 Liter VVT Engine SAE international 200401-3054, Powertrain \& Fluid Systems Conference and Exhibition Tampa, Florida USA October 25-28, 2004

[12] Gisca V, Mereacre A. and Pisarenco M., (2004) Utilization of Neural Networks for Observing the Internal Combustion Engine's Function, $7^{\text {th }}$ International cConference on Development and Application Systems, Suceava, Romania, May 27-29.

[13] Garg, A. B., Diwan, P., Saxena, M., Artificial Neural Networks Based Methodologies For Optimization of Engine Operations (2012), International Journal of Scientific \& Engineering Research, Volume 3, Issue 5, May

[14] He Y., Rutland C. J.(2004), Application of artificial neural networks in engine modeling, International Journal of Engine Research, 5: 281

[15] Haykin, S., (1998) Neural Networks - A comprehensive foundation, Prentice-Hall 